\title{
Hallazgos endoscópicos del tumor mucinoso de páncreas
}

\author{
E. Ubiña Aznar, R. Rivera Irigoin, I. Méndez Sánchez, N. Fernández Moreno, G. García Fernández y \\ A. Sánchez Cantos
}

Servicio de Aparato Digestivo y Anatomía Patológica. Hospital Costa del Sol. Marbella, Málaga

Paciente de 55 años de edad con antecedentes de hipotiroidismo, hipertensión arterial y ligadura tubárica que ingresa por cuadro de ictericia de más de una semana de evolución junto con disconfort epigástrico y astenia. En la exploración física sólo destacaba discreto tinte ictérico en escleras, sin presentar otros signos. Las pruebas complementarias realizadas evidenciaban una hipertransaminasemia (GOT: 99 U/L, GPT: 344 U/L) asociada a una elevación de las enzimas de colestasis (FA: $302 \mathrm{U} / \mathrm{L}$, GGT: $357 \mathrm{U} / \mathrm{L})$ y un discreto aumento de la bilirrubina $(2,42 \mathrm{mg} / \mathrm{dl})$; el resto de parámetros analíticos que incluían hemograma, estudio de coagulación y marcadores tumorales fueron normales. Se realizaron estudios de imagen mediante ecografía y tomografía axial computerizada que denotaban la presencia de una marcada dilatación del colédoco y del conducto pancreático principal junto con una lesión de aspecto quístico en la cabeza pancreática (Fig. 1). La colangiopancreatografía por resonancia magnética (CPRM) detectaba una lesión compleja de naturaleza quística en la encrucijada hepatoduodenopancreática que comunicaba con el extremo distal del Wirsung, junto con dilatación de los conductos biliares y pancreáticos. La colangiopancreatografía retrógrada endoscópica (CPRE) permitió identificar el signo patognomónico de esta entidad, que fue la salida de material mucoide a través de la papila, además de la presencia de una dilatación de todo el conducto pancreático principal (Fig. 2). La paciente durante el ingreso hospitalario presentó resolución espontánea de la ictericia en probable relación a fístula biliodigestiva y fue valorada por el Servicio de Cirugía que indicó pancreatectomía total.

El tumor mucinoso papilar intraductal del páncreas (TMPI) es una infrecuente entidad quística, maligna o premaligna del páncreas; consiste en una hiperplasia del epitelio de los conductos pancreáticos, que ocasionan hipersecreción de moco produciendo una obstrucción sintomática de estos, junto con lesiones quísticas y dilatación del conducto pancreático principal secundario a la entrada de moco procedente de las ramas secundarias afectas (1). Este tipo de tumor representa el 1-2\% de los tumores pancreáticos exocrinos y el $12 \%$ de los tumores quísticos pancreáticos (2). La CPRE se ha considerado la técnica de elección en el diagnóstico de los TMPI, ya que identifica la salida de material mucoide a través de la papila y permite visualizar la dilatación del conducto pancreático principal, así como la presencia de ramas colaterales ectásicas $(2,3)$.

El diagnóstico diferencial de esta entidad debe realizarse con las masas quísticas pancreáticas como son el cistoadenoma mucinoso y cistoadenocarcinoma, cistoadenoma seroso y el pseudoquiste pancreático (1). Aunque el tratamiento es un tema controvertido, el potencial de malignización de estas lesiones hace que la resección quirúrgica temprana sea el tratamiento de elección (4).

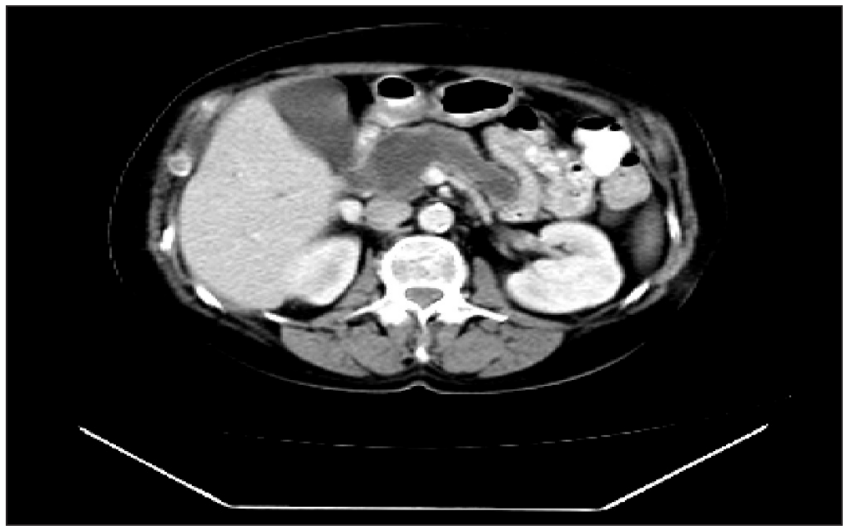

Fig. 1. TAC: importante dilatación del colédoco y conducto pancreático.

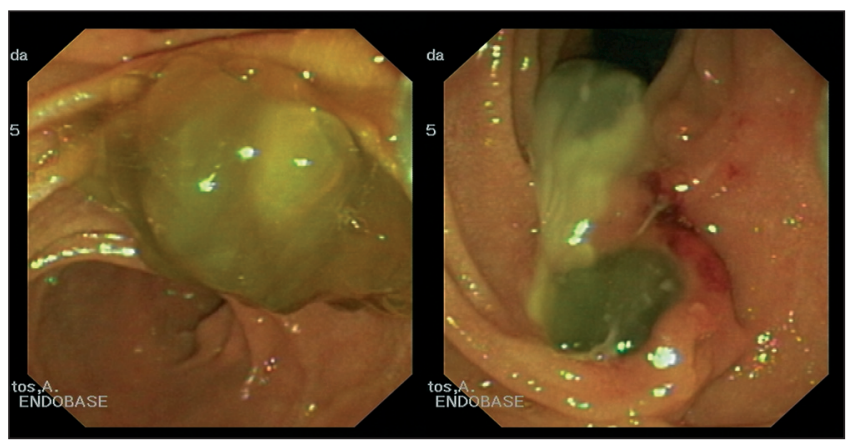

Fig. 2. CPRE: salida de material mucoide por la papila de Vater. 


\section{BIBLIOGRAFÍA}

1. Fernández Esparrach G, Pellisé M, Ginés A. Tumor mucinoso papilar intraductal del páncreas: una entidad más desconocida que infrecuente. Gastroenterol Hepatol 2003; 26 (9): 562-70.

2. Nickl NJ, Lawson JM, Cotton PB. Mucinous pancreatic tumors: ERPC findings. Gastrointest Endosc 1991; 37: 133-8.

3. Yamaguchi K, Tanaka M. Mucin-hypersecreting tumor of the páncreas with mucin extrusion through an enlarged papilla. Am J Gastroenterol 1991; 86: 835-9.

4. Falconi M, Salvia R, Bassi C, Zamboni G, Talamini G, Pederzoli P. Clinicopathological features and treatment of intraductal papilar mucinous tumour of the páncreas. Br J Surg 2001; 88: 376-81. 